\title{
Quantitative measurement of abnormal retinal correspondence
}

\author{
G. C. SOOD, D. K. SEN, D. K. JAIN, AND BALJIT SINGH \\ Department of Ophthalmology, Maulana Azad Medical College, New Delhi, India
}

Since Müller (1826) first drew attention to the phenomenon of abnormal retinal correspondence, several methods of diagnosis have been described. This paper describes two $\vec{O}$ ways of measuring the degree of abnormal retinal correspondence by the after-image test.

\section{Method}

With the help of slides in the synoptophore after-images are produced in the two eyes successively. The patient is asked to concentrate on the central red spot of the bright streak of light with each eye $\underline{\mathbb{N}}$ in turn for 30 sec. The horizontal streak of light is used for the "better eye" and the vertical streak $\overrightarrow{0}$ for the "worse" eye. The after-images are made prominent by using the ordinary blinkers provided. in the synoptophore, and the patient is asked to note the position of the after-images in relation to each other. In normal retinal correspondence the vertical image passes through the centre of the horizontal image, forming a symmetrical cross. In abnormal retinal correspondence the verticalo streak is seen at one side or the other, forming an asymmetrical cross.

\section{Measurements}

The amount of displacement of the vertical streak can be measured in two ways:

\section{(I) Using the angle Kappa slide in the synoptophore}

The slide used to measure the angle Kappa is put in front of the better eye. The patient: is asked to look at the zero and to indicate the number or letter where the vertical image crosses the horizontal scale. On one side of the zero there are numbers " $I$ " to " 9 " and₹ on the other side letters " $A$ " to " $I$ ". As each letter or number represents $I$ ", the amounto of abnormal retinal correspondence can be measured directly in degrees.

\section{(2) Using the Tangent Scale}

The patient is asked to project the after-images on a Maddox Tangent Scale from a distancen of $5 \mathrm{~m}$. The room is made sufficiently dark and the central spotlight on the tangent scale is lighted at minimum intensity to avoid interference with the formation of the after-images 0 The patient is asked to fix the central spotlight with the better eye and to note the numbefo at which the vertical image crosses the scale. This number gives the amount of abnormal retinal correspondence in degrees.

\section{Observations}

Abnormal retinal correspondence was diagnosed and measured quantitatively in nineteen ${ }^{\mathbb{Q}}$ 
cases. Small degrees of abnormality were found to be more common, and in eight of the nineteen cases the angle of anomaly was between $1^{\circ}$ and $3^{\circ}$ (Table).

Table Degree of abnormal retinal correspondence in I 9 cases

\begin{tabular}{|c|c|c|c|c|c|}
\hline Type of squint & $1^{\circ}-3^{\circ}$ & $4^{\circ}-6^{\circ}$ & $7^{\circ}-9^{\circ}$ & Above $9^{\circ}$ & Total \\
\hline Divergent & 8 & o & 2 & 6 & I6 \\
\hline Convergent & 0 & $\mathbf{I}$ & $\mathbf{o}$ & 2 & 3 \\
\hline Total & 8 & I & 2 & 8 & I9 \\
\hline
\end{tabular}

\section{Comment}

Both these methods have been used to measure abnormal retinal correspondence and it was found that the first method, using the synoptophore with the angle Kappa slide, was more convenient, accurate, and reliable as it does not entail moving the patient.

After-images can be made more prominent and persistent with the blinkers provided in the synoptophore, and this method is particularly useful when the after-images are shortlived.

Previous workers have generally ignored cases in which the angle of anomaly was less than $5^{\circ}$ because they thought it could be due to an individual error of judgement, but by the methods described above it is possible to measure an abnormality of $\mathrm{I}^{\circ}$ or less.

\section{Summary}

Two methods of measuring abnormal retinal correspondence in degrees are described.

We acknowledge with gratitude the help given by the Director of the Indian Council for Medical Research by providing the funds for this study.

\section{References}

DUKE-ELDER, s. (1949) “Text-book of Ophthalmology", vol. 4, p. 3850 . Kimpton, London MÜLLER, G. (1826) "Zur vergleichenden Physiologie des Gesichtssinnes des Menschen und der

Thiere". Cnobloch, Leipzig (Cited by Duke-Elder, 1949) 